TM-1621

\title{
Tests of High Gradient Superconducting Quadrupole Magnets for the Tevatron*
}

\author{
M. J. Lamm, J. Carson, S. Gourlay, R. Hanft, \\ K. Koepke, P. Mantsch, A. D. McInturff, A. Riddiford, and J. Strait \\ Fermi National Accelerator Laboratory \\ P.O. Box 500, Batavia, Illinois 60510
}

September 1989

* Presented at the Cryogenic Engineering Conference, Los Angeles, California, July 24-28, 1989.

달 Operated by Universitles Research Association, Inc., under contract with the United States Department of Energy 


\title{
TESTS OF HIGH GRADIENT SUPERCONDUCTING QUADRUPOLE
} MAGNETS FOR THE TEVATRON

M. J. Lamm, J. Carson, S. Gourlay,

R. Hanft, K. Koepke, P. Mantsch,

A. D. McInturff, A. Riddiford, and

J. Strait

Fermi National Accelerator Laboratory*

Batavia, Illinois

\begin{abstract}
Tests have been completed on three prototype magnets and two production magnets to be used for the Tevatron $D \phi / B \phi$ low- $\beta$ insertion. These cold iron, two shell quadrupoles are made of 36 strand Rutherford type $\mathrm{NbTi}$ superconducting cable. Magnet field gradients well in excess of the design $1.41 \mathrm{~T} / \mathrm{cm}$ have been achieved at a transfer function of 0.291 $\mathrm{T} / \mathrm{cm} / \mathrm{kA}$. Quench performance at $4.2 \mathrm{~K}$ and $3.7 \mathrm{~K}$ and magnetic multipole measurement data are presented and discussed.
\end{abstract}

\section{INTRODUCTION}

The Tevatron D low- $\beta$ upgrade ${ }^{1}$ calls for the construction and installation of two shell high gradient superconducting quadrupoles, low current single shell high gradient correctors ${ }^{2}$ and conventional Tevatron correction coils at the $D \phi$ intersection region. A complementary system will also be installed at the $B \phi$ intersection to replace the present $B \emptyset$ low- $\beta$ system $^{3,4,5}$. The purpose of the $D \phi / B \phi$ low- $\beta$ insertions is to improve the beam luminosity for proton - antiproton particle interactions in the $D \emptyset$ and $\mathrm{B} \phi(\mathrm{CDF})$ detectors.

For $1 \mathrm{TeV}$ Tevatron operation in the colliding beam mode, the high gradient quadrupoles of the low- $\beta$ insertion need to operste up to the design field gradient of $1.41 \mathrm{~T} / \mathrm{cm}$ at $4.8 \mathrm{~K}$ with multipole harmonics that are comparable to those in the present $B \emptyset$ low- $\beta$ system. While good quench training is not essential due to the limited number of magnets involved, it is important that the magnets remember their training through a thermal cycle. Finally, these magnets must be able to withstand a spontaneous quench over the full range of operating currents. Quench protection uses their built in quench heaters plus an improved version of the existing quench protection circuitry in the Tevatron. Test results are reported that demonstrate the magnets' ability to meet these criteria.

*Operated by Universities Research Association under contract with the U.S. Department of Energy 


\section{DESCRIPTION OF MAGNETS}

A cross section of the magnet is shown in Figure 1. The inner diameter of the coil is $7.62 \mathrm{~cm}$. Both the 19 turn inner and 28 turn outer coils consist of 36 strand superconducting $\mathrm{NbTi}$ cable. The location of a copper wedge in the inner and outer coils was chosen to reduce the geometric 12 and 20 poles. The collars are made of 16 gauge aluminum alloy (2024-T3) and are locked in place with square keys. On one magnet, 127 micron collar shims were applied in order to increase the collar prestress. The yoke consists of 16 gauge low carbon, high quality magnetic steel laminations with inner and outer diameters of $17.0 \mathrm{~cm}$ and $26.7 \mathrm{~cm}$ respectively. Two stainless steel heaters, of 25.4 micron thickness, were installed between the coil and the collars (in the ground wrap) for quench protection. A 304 stainless steel skin surrounds the yoke and is seam welded longitudinally to secure the yoke.

The magnet was equipped with voltage taps on the splice between each $1 / 8$ magnet coil and on the magnet leads. The voltage taps enabled us to determine the coil in which a quench occurred. The center splice and lead voltage taps were also used for quench protection. The production magnets range from $61 \mathrm{~cm}$ to $589 \mathrm{~cm}$ in magnetic length with operating currents that range from 2011 A to 4832 A as specified by the low- $\beta$ lattice design ${ }^{\circ}$. See Table 1. The peak operating current of 4830 A corresponds to a gradient of $1.41 \mathrm{~T} / \mathrm{cm}$. The two production magnets that have been tested so far will have peak operating current of either 2011 or 2821 A, depending on where they are used in the lattice.

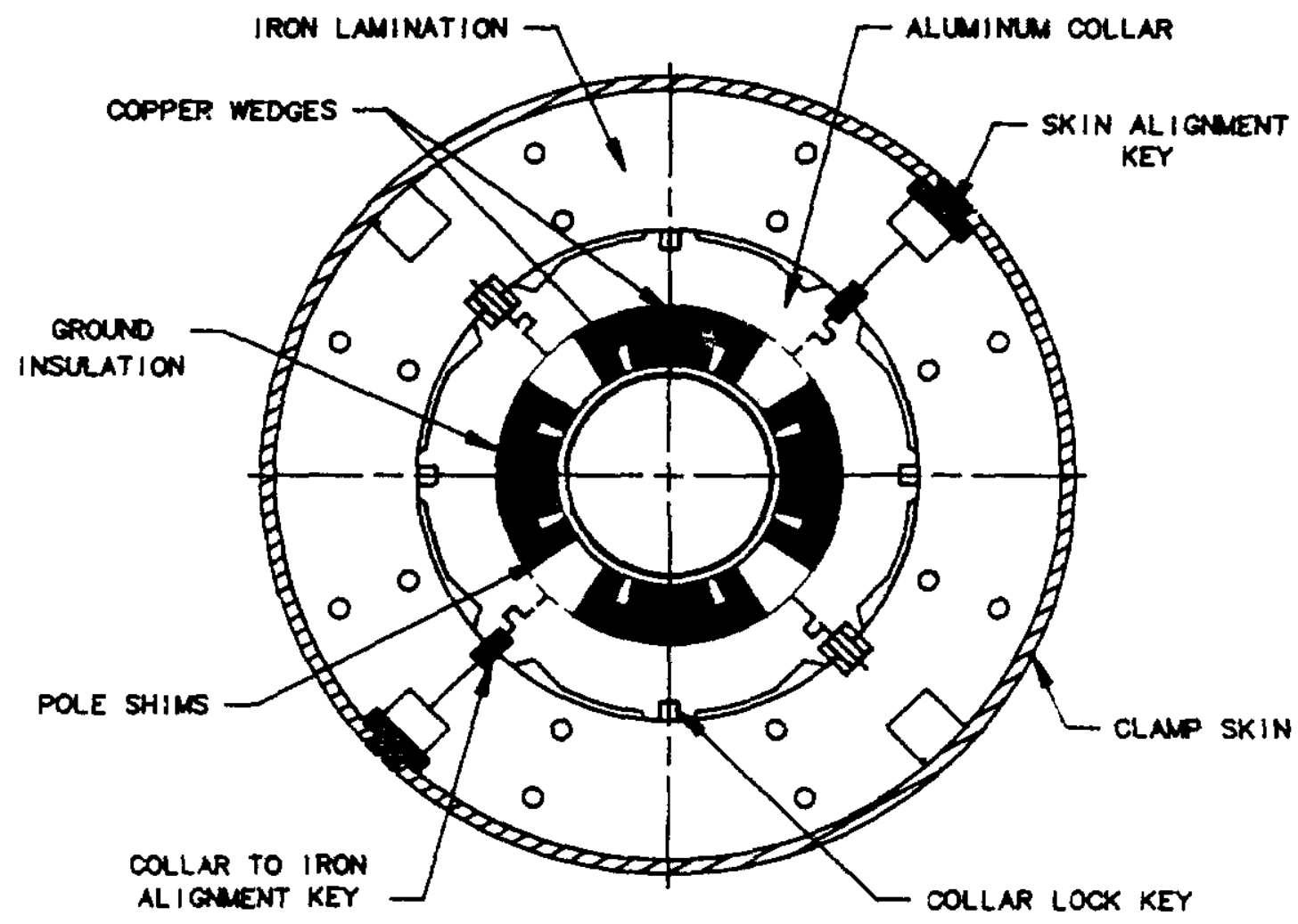

Fig. 1. Cross section of the high gradient superconducting quadrupole. The coil inner diameter is $7.62 \mathrm{~cm}$. The skin outer diameter is $27.62 \mathrm{~cm}$ 
Table 1 The Gradient Specifications For the $D \phi / B \emptyset$ low- $\beta$ Quadrupoles at $1 \mathrm{TeV}$.

Magnetic length No. Req'd Operating Current Operating Gradient

$(\mathrm{cm})$

$60.1 \mathrm{~cm}$

$137.2 \mathrm{~cm}$

$335.3 \mathrm{~cm}$

$589.3 \mathrm{~cm}$
(A)

4
$4 / 4$
8
4

4832

$2821 / 2011$

4811

4746
$(\mathrm{T} / \mathrm{cm})$

1.41

$0.82 / 0.59$

1.41

1.38

Prior to the construction of the first production magnet, several $112 \mathrm{~cm}$ prototypes were built. The principle difference between these prototypes and the production magnets is the quality of the conductor. Table 2 is a summary of the cable properties for the model and production magnets. In general, the prototypes were made from cable with a $600 \mathrm{~A}$ lower critical current at $4.2 \mathrm{~K}$ than the production magnets.

\section{TEST FACILITY}

The magnets were tested in a 3.6 meter long vertical Dewar located in the Magnet Development Laboratory at Fermilab. The Dewar was instrumented with pressure transducers and liquid helium level gages. The shell of each magnet was instrumented with carbon thermometers that were accurate to $\pm 10 \mathrm{mK}$. The temperature of the Dewar could be lowered to approximately $3.2 \mathrm{~K}$ by pumping directly on the liquid helium bath with a vacuum pump.

Current was supplied by Transrex 500-5 power supplies. When performing quench studies, two supplies were operated in parallel with a current capacity in excess of $10,000 \mathrm{~A}$ and a current regulation to better than 1 A. For magnetic measurements where current stability was more critical, one supply was used. In this case, the current regulation was within $0.1 \mathrm{~A}$. Quench data was collected with a CAMAC based data acquisition system modeled after the system used in the Fermilab Magnet Test Facility ${ }^{4,8}$.

Magnetic measurements were performed with a multiple winding Morgan coil inserted into an anti-cryostat, which in turn, was inserted into the magnet. The Morgan coil was rotated at approximately $6 \mathrm{~Hz}$, and the resultant voltages were processed by a V/F converter based measuring system?.

Table 2 Properties of Superconducting Cable

Prototype Material

Cu/SC
Estimated RRR
Filament size
No, of Filaments
Strand diameter
Twists/cm
No. of Strands
Ic ( $6 \mathrm{~T}, 4.2 \mathrm{~K}$
Peff $2 \times 10 * *-120 \mathrm{hmcm})$

$10^{1.73 / 1}$

12.5 microns

660

533 microns

0.4

36

$5.3 \pm .33 \mathrm{kA}$
Production Material

$100^{1.5 / 1}$

13 microns

613

533 microns

0.8

36

$7.56 \mathrm{kA}$ 
The anti-cryostat consisted of two concentric seamless stainless steel shells. The space in between the two shells was filled with ouperinsulation, and evacuated while the magnet was at cryogenic temperatures. The inner cylinder of the anti-cryostat was also evacuated during all quench tests to minimize the heat load on the coils.

\section{TEST RESULTS}

The five magnets had the following teats performed. First, with the magnet cooled to $4.2 \mathrm{~K}$, the magnet was ramped at a nominal ramp rate until a quenched occurred. This procedure was continued until a quench plateau was established. The magnet was then quenched at ramp rates . from $12 \mathrm{~A} / \mathrm{sec}$ to $200 \mathrm{~A} / \mathrm{sec}$. Then each magnet was cooled to a lower temperature, either $3.2 \mathrm{~K}$ or $3.7 \mathrm{~K}$, in order to study the quench curreri temperature dependence. Magnetic measurements were performed at $4.2 \mathrm{~K}$ to determine the magnet's field quality over the full range of operating currents. For one prototype and one production magnet, extensive tests were performed on the quench protection heaters. The results of these tests indicate that the stainless uteel heaters, in combination with the existing quench detection circuitry and heater power supplies, were able to protect these magnets. Finally, four of the five magnets were retested after a room temperature thermal cycle.

\section{Quench Performance}

Table 3 shows a summary of the quench current behavior. Figure 2 shows the detailed quench history and short sample quench predictions for both production magnets. All of the prototype magnets reached their plateau current in less than 10 quenches. The first production magnet (designated N5401F) reached its plateau $600 \mathrm{~A}$ above the best prototype quench current, but required 15 training quenches. In an attempt to improve the training performance, 127 micron shims were placed between the collar and the coil on the second production magnet (designated N5403F). We had hoped that the increase in the coil prestress would constrain conductor movement and make training quenches less likely. Magnet N5403F did plateau in only 4 quenches but. only reached a quench plateau current of $5080 \mathrm{~A}, 250 \mathrm{~A}$ lower than magnet N5401F. The difference in quench current appears to be due to the conductor. The effect of the shims on training was not dramatic since it took the unshimmed magnet 6 quenches to reach $5080 \mathrm{~A}$ compared to 4 quenches with the shimmed magnet.

Table 3 Summary of the Quench Current, Training History, and Short Sample Predictions at $4.2 \mathrm{~K}$

Magnet Quench Current $\begin{aligned} & \text { Short Sample No. of Quenches } \\ & \text { Prediction }\end{aligned}$

\author{
To Plateau
}

No. of Quenches

To Plateau after

Thermal Cyclo

$\begin{array}{llcll}\text { Proto } 1 & 4540 & 4600-4800 & 5 & 0 \\ \text { Proto 2 } & 4590 & 4600-4800 & 8 & 0 \\ \text { Proto 3 } & 4790 & 4600-4800 & 7 & 1 \\ & & 5270 & 15 & 3 \\ \text { N5401F } & 5400 & 5230 & 4 & \mathrm{n} / \mathrm{a}\end{array}$



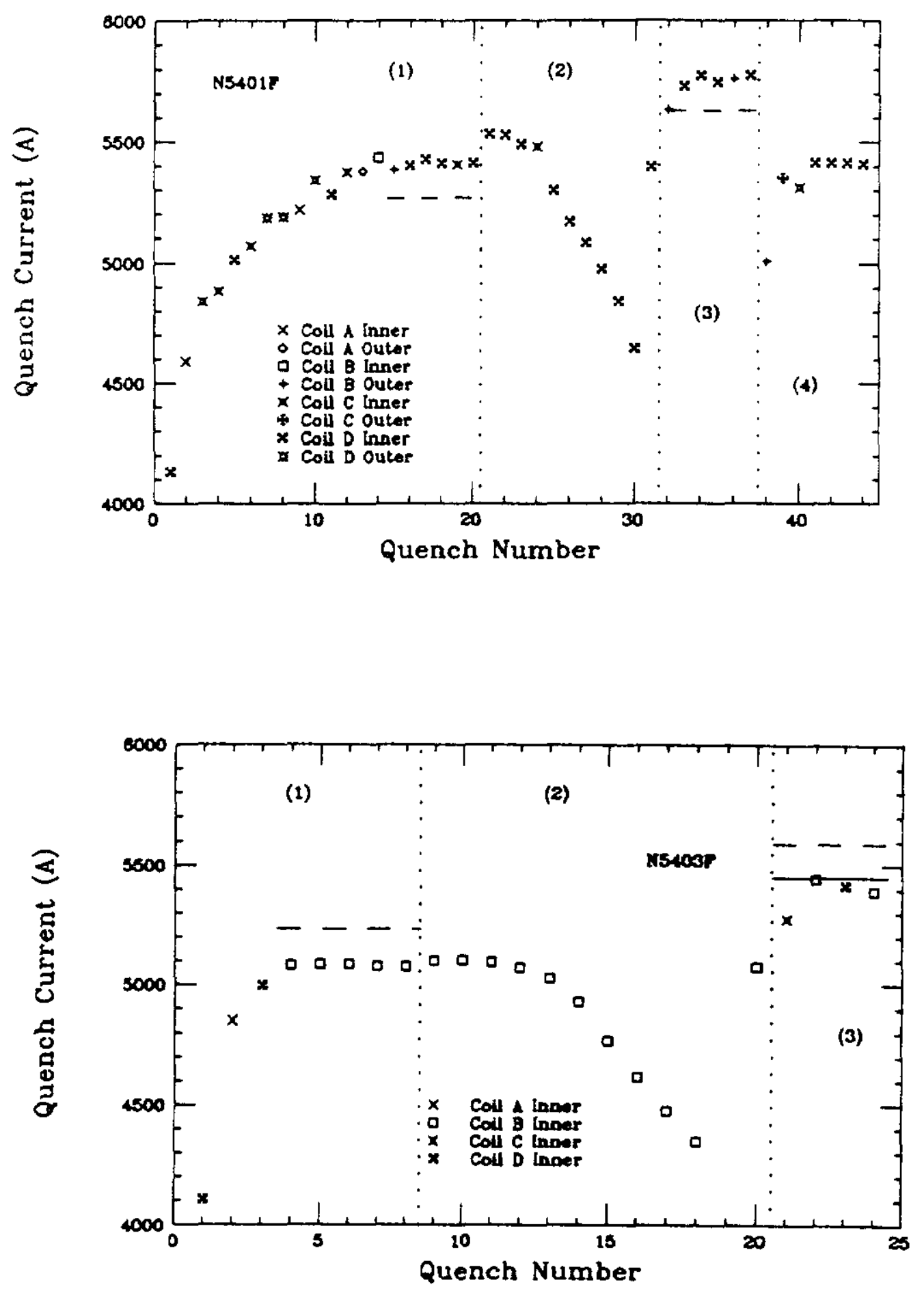

Fig. 2. Quench history for two production magnets N5401F and N5403F; (1) Initial $4.2 \mathrm{~K}$ plateau at $50 \mathrm{~A} / \mathrm{sec}$, (2) Ramp rate studies see also Figure 3 , (3) $3.7 \mathrm{~K}$ plateau, (4) $4.2 \mathrm{~K}$ plateau after thermal cycle for N5401F. Dashed lines are the short sample predictions. For N5403F, the solid line is the $3.7 \mathrm{~K}$ prediction based on the measured $4.2 \mathrm{~K} 5080 \mathrm{~A}$ quench plateau. 


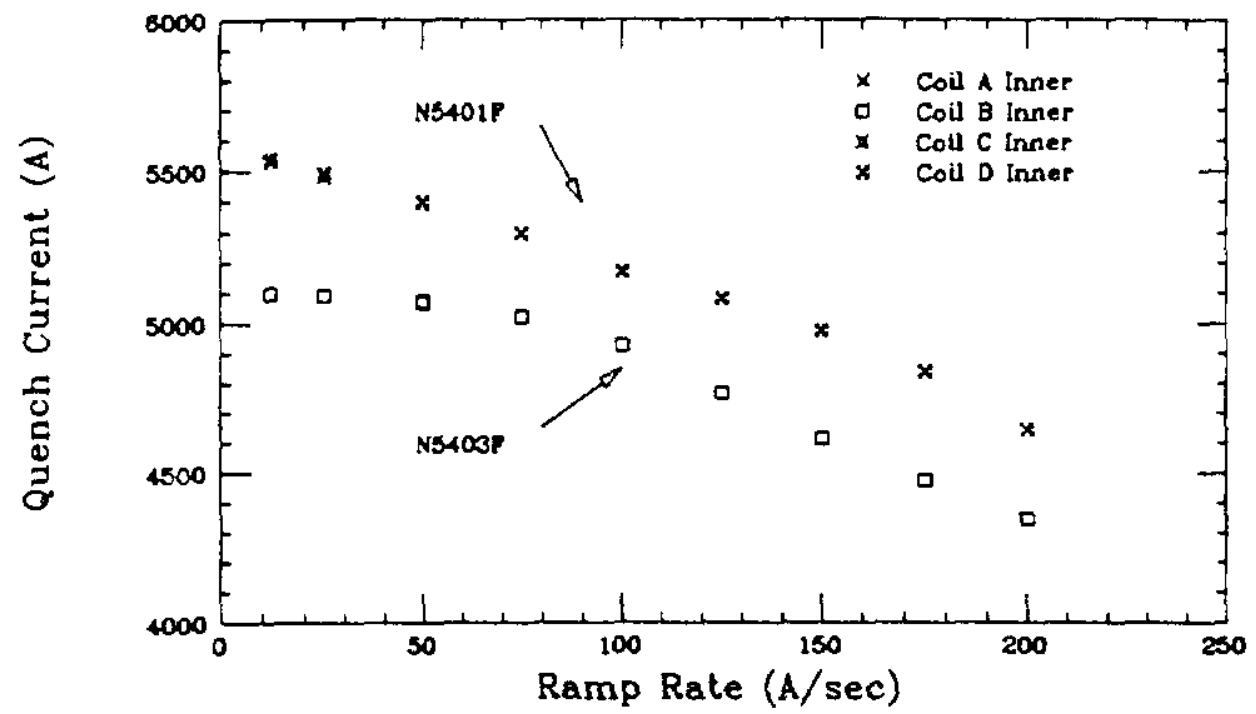

Fig. 3. Ramp rate studies for the two production magnets.

The quench current vs ramp rate dependence for the two production magnets is shown in Figure 3 . There is a monotonic decrease of quench current with ramp rate. The fall off starts from a flattop at low ramp rate which is dictated by the magnet's short sample limit. All of the magnets have approximately the same ramp rate dependence between $100 \mathrm{~A} / \mathrm{sec}$ and $200 \mathrm{~A} / \mathrm{sec}$. In the prototype magnets the high ramp rate quenches occurred in a different coil than the low ramp rate, short sample, limited coil. Studies are on-going to understand this effect.

\section{Harmonics Measurements}

The magnetic field can be described by the following definition:

$$
B x-i B y=B_{1}^{*} R_{0} \sum_{n=0}^{\infty}\left(a_{n}-i b_{n}\right) *\left((x+i y) / R_{0}\right)^{n}
$$

$\left(B_{1}\right)$ is the field gradient of the quadrupole field. $\left(a_{n}\right)$ and $\left(b_{n}\right)$ are the skew and normal coefficents and $\left(R_{0}\right)$ is a reference radius chosen to be 2.54 $\mathrm{cm}$ ( 1 inch) for the Tevatron. For the purpose of these tests, the definition of the $x$ and $y$ directions are chosen so that the skew quadrupole term ( $a_{1}$ ) is zero. The definition of the $x$ and $y$ axis has a two-fold ambiguity due to the two-fold current symmetry. For a perfectly constructed quadrupole with two-fold current symmetry and four-fold geometric symmetry, the skew terms vanish, and only normal terms with $n=4 M+1 \quad(M=0,1,2 \ldots)$ can exist. These are referred to as "allowed" multipoles. Note that the two-fold ambiguity means that there is a sign ambiguity for $n=2 M(M=0,1,2 \ldots)$ nonallowed multipoles. It is customary to define the magnetic field coefficents in units of $10^{4}$ times the ratio of the multipole field (evaluated at the reference radius, $2.54 \mathrm{~cm}$ ) to the quadrupole field gradient.

Table 4 shows a summary of the geometric harmonics measured for the five magnets with a comparison to the nine quadrupoles built for the existing $B \emptyset$ low $\rho$ insertion. Note that the 12 pole for $\mathrm{N} 5403 \mathrm{~F}$ is 2.5 units larger than N5041F which is due to the additional collared shims, as expected. The non-allowed harmonics are comparable to those of the nine $\mathrm{B} \phi$ magnets measured. 
TABLE 4 Summary of the Geometric Multipoles For the High Gradient Quadrupoles

Harmonic

Magnet

$\begin{array}{lrrrr}\text { Units at 2.54 cm } & \text { N5401F } & \text { N5403F } & \begin{array}{l}\text { Prototype } \\ \text { Average* }\end{array} & \begin{array}{c}\text { B } \emptyset \text { Quad } \\ \text { Average* }\end{array} \\ \text { Normal Sex. } & 2.5 & -0.5 & 2.5 \pm 1.3 & -1.0 \pm 2.6 \\ \text { Skew Sex. } & -1.8 & -0.6 & 2.5 \pm 2.5 & 3.3 \pm 2.4 \\ \text { Normal Dct. } & -1.6 & -0.1 & 1.2 \pm 1.0 & 0.6 \pm 0.6 \\ \text { Skew Oct. } & -1.9 & -1.2 & 2.3 \pm 1.9 & 1.1 \pm 2.5 \\ \text { Normal Dec. } & 0.0 & +0.3 & 0.2 \pm 0.2 & -0.2 \pm 0.8 \\ \text { Skew Dec. } & -0.2 & -1.2 & 0.2 \pm 0.2 & -1.0 \pm 0.8 \\ \text { Normal 12 } & -1.0 & +1.5 & 2.5 \pm 1.2 & 2.1 \pm 1.2 \\ \text { Skew 12 } & -0.1 & 0.0 & 0.4 \pm 0.2 & 0.1 \pm 0.2 \\ \text { Normal 14 } & +0.3 & -0.1 & 0.1 \pm 0.1 & 0.0 \pm 0.1 \\ \text { Skew 14 } & -0.4 & -0.3 & 0.1 \pm 0.1 & 0.0 \pm 0.2\end{array}$

(*) Statistical errors only

The transfer function is measured to be $.292 \mathrm{~T} / \mathrm{cm} / \mathrm{kA}$ at $2000 \mathrm{~A}$ which is in good agreement with the design specification. The measured deviation from linear between 1000 and $5000 \mathrm{~A}$ is less than our one percent measurement uncertainty. Figure 4 is a plot of the 12 pole as a function of current. Superimposed over the plot is the average 12 pole measured in the Bq magnets, with the level of the geometric 12 pole adjusted to agree with this magnet. The widths of the 12 pole are comparable.

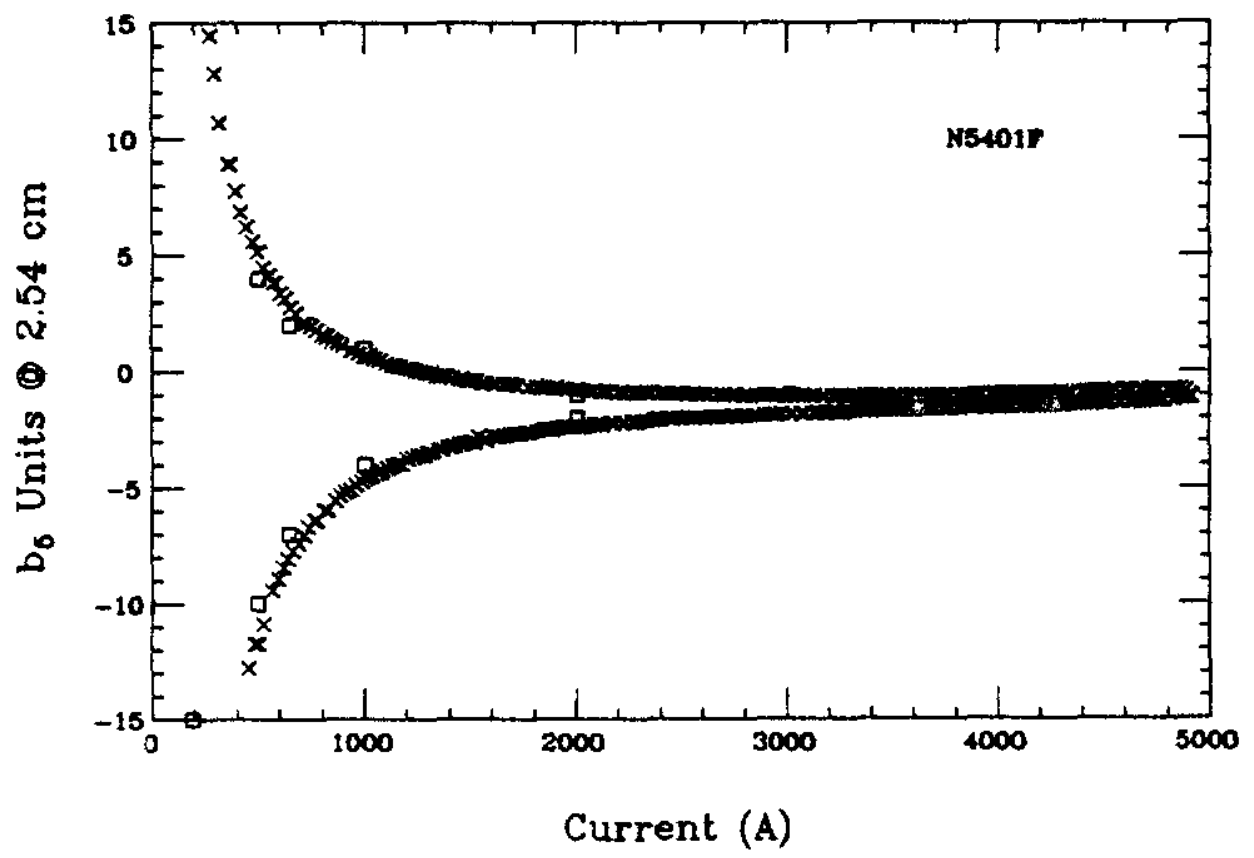

Fig. 4. Normalized 12 pole (b5) as a function of current. The average normalized 12 pole from $B O$ qudrupoles is superimposed, with the height adjusted for the difference in geometric 12 pole. 
Three $112 \mathrm{~cm}$ prototypes and the first two $137 \mathrm{~cm}$ production magnets have been tested in a vertical Dewar at $4.2 \mathrm{~K}$ degrees and below. These magnets exhibited significant training requiring up to 15 quenches to reach plateau. For the two production magnets, only one training quench was required to reach the design field gradient of $1.41 \mathrm{~T} / \mathrm{cm}$. Four of the five magnets were retested after thermal cycle. None of the prototypes needed to be retrained, while one of the production magnets required 3 training quenches. All of the retraining quenches were above the design field gradient of $1.41 \mathrm{~T} / \mathrm{cm}$. All of the magnets exhibited a ramp rate dependence of the quench current at ramp rates above $50 \mathrm{~A} / \mathrm{sec}$. The highest gradients are required only in the Tevatron colliding beam mode which does not require a fast ramp rate. Of the two production magnets, one is expected to have a quench current at $4.8 \mathrm{~K}$ which would allow the magnet to operate at $1.41 \mathrm{~T} / \mathrm{cm}$. During Tevatron operation, these $137 \mathrm{~cm}$ quadrupoles will only be required to operate at half this gradient.

The harmonics were measured up to the 14 pole on all magnets. The calculated transfer function of $.291 \mathrm{~T} / \mathrm{cm} / \mathrm{kA}$ was achieved. The level of the higher order multipoles is consistent with previous Fermilab low- $p$ quadrupoles and is considered acceptable. Studies with the stainless steel strip heaters have shown that the magnet can be protected from quench overheating using the existent Tevatron quench protection scheme.

\section{ACKNOWLEDGEMENTS}

We would like to thank the Fermilab Technical Support Section, in particular the personnel of the Magnet Development Laboratory, for their assistance in making these tests possible.

\section{REFERENCES}

1. A. D. McInturff et al.,"The Fermilab collider DQ Low Beta System", European Particle Accelerator Conference, Rome, Italy, 1988 (to be published)

2. P. M. Mantsch et al.,"A New High-Gradient Correction Quadruople for The Fermilab Luminosity Upgrade", Particle and Accelerator Conf., Chicago, Il, 1989 (to be published)

3. D. Johnson, IEEE "The $B \varnothing$ Low Beta Insertion Design For the Tevatron", Trans. on N.S., NS-32, 1672, (1985)

4. K. Koepke, H. E. Fisk, G. Mulholland, H. Pfeffer, "The Tevatron B $\phi$ Low Beta System", IEEE Trans. on N.S., NS-32, 1675, (1985)

5. D. Finley, R. Johnson and F. Willeke,"Control and Initial Operation of the Fermilab Low Beta Insertion", IEEE Trans. on N.S., NS-32, $1678,(1985)$

6. "Tevatron Low-Beta Quadruole Requirements and Specification" January 23, 1989

7. K. McGuire, et al., "Cryogenic Instrumentation of an SSC Magnet Test Stand", Adv. Cryo. Engr. 33, 1063 (1988)

8. J. Strait, et al." "Fermilab R\&D Test Facility for SSC Magnets", Presented at the 1989 International Industrial Symposium on the Super Collider, New Orleans, LA, February 8-10, 1989 (Fermilab preprint TM-1563)

9. G. H. Morgan. "Stationary coil for Measuring the Harmonics in Pulsed Transport Magnets", Proc. Inter. Conf. on Magnet Technol, edited by Y. Winterbottom p.787, 1972 